\title{
Administração Pública gerencial e o princípio democrático: implicações e desafios
}

ManagerialPublic Administration and the requirements of the democratic principle: implicatio ns and challenges

\section{Andrea Maria Sobreira Karam ${ }^{1}$ Clarissa Sampaio Silva ${ }^{2}$}

RESUMO: Pretende-se, por meio do presente artigo, verificar, no contexto da Administração Pública brasileira, os desafios e as implicações da adoção do modelo gerencial introduzido pela Reforma Administrativa trazida pela Emenda Constitucional n. 19/98, em conjugação com o princípio democrático e com aqueles do art. 37, caput da $\mathrm{CF} / 88$. Abordar-se-á brevemente o contexto do surgimento do modelo de organização gerencial, na perspectiva mundial e no âmbito brasileiro, os paradigmas e as exigências; as formas de manifestação do princípio democrático no âmbito administrativo, os desafios e limites encontrados. Como resultados, tem-se a modificação das estruturas administrativas; o desenvolvimento da ideia de accontability, aspecto da governança corporativa; da busca de consensos, acompanhados de instrumentos para ensejar a participação cidadã na formação da vontade estatal, além da possibilidade de resolução de conflitos para com o Poder Público por meio da autocomposição. As formas de participação do cidadão na construção das decisões administrativas devem ser compatíveis com os objetivos maiores a serem realizados pela Administração Pública, a eles se ajustando, de modo a se ajustar aos contornos do princípio democrático.

\section{Palavras-chave: Administração}

Pública

Brasileira.

Princípio

Democrático. Desafios. Implicações.

ABSTRACT: The purpose of this article is to verify, in the context of the Brazilian Public Administration, the challenges and implications of adopting the managerial model introduced by

\footnotetext{
${ }^{1}$ Mestre em Direito Constitucional pela Universidade de Fortaleza- UNIFOR, Supervisora do Núcleo de Pesquisa e Extensão da Academia Estadual de Segurança Pública do Ceará- AESP|CE, Docente do Curso de Direito da Faculdade do Maciço do Baturité.
}

${ }^{2}$ Doutora em Ciências Jurídico-Politicas pela universidade de Lisbo. Docente na Universidade de Fortaleza UNIFOR. Advogada da União. 
the Administrative Reform brought by Constitutional Amendment 19/98, in conjunction with democratic principle and with those of the art.37, caput da CF. It will briefly address the context of the emergence of the model of managerial organization, in the global perspective and in the Brazilian context, the paradigms and requirements; how the democratic principle appears in the administrative field, along with its challenges and limits. As a result, there is a change in the administrative structures; the development of the idea of accountability, aspect of corporate governance; the search for consensus, accompanied by instruments to encourage citizen participation in the formation of the state will, as well as the possibility of resolving conflicts with the Public Power through self-determination. The forms of citizen participation in the construction of administrative decisions must be compatible with the larger objectives to be achieved by the Public Administration to which they must adjust.

Key words: Brazilian Public Administration. Democratic principle. Challenges. Implications.

\section{INTRODUÇÃO}

O Estado Democrático de Direito reclama um modelo organizacional aplicável à Administração Pública compatível com seus objetivos e princípios. Busca-se assim um novel modelo administrativo que celebre a democracia e, ao mesmo tempo, proporcione a segurança jurídica e demais valores constitucionais.

Mirando para o contexto histórico brasileiro, sucederam-se, na Administração Pública, práticas patrimonialistas, marcadas pela confusão entre as esferas pública e privada, e, depois, burocráticas, ${ }^{3}$ as quais serviram como instrumento jurídico formal para manutenção do poder, com sacrifício do exercício da cidadania.

Todavia, dentro da Administração Pública de um Estado Democrático de Direito faz-se necessário instaurar novos hábitos no bojo das relações administrativas, e livrar-se dos males decorrentes de práticas patrimonialistas e da estrita visão que não se compromete com os resultados a serem alcançados. Uma realidade que requer mudança para a legitimação do atuar administrativo (FREITAS, 2007, p.17).

Sob essa perspectiva, a reforma administrativa, que resultou na Emenda Constitucional $\mathrm{n}$. 19/1998, surge com o objetivo de superar os problemas da estrutura organizacional burocrática presente na administração pública até os dias atuais no cenário brasileiro.

\footnotetext{
${ }^{3}$ Sobre o assunto vide Faoro, (2001).
} 
E, segundo Abrucio (1997, p. 7), o modelo gerencial objetiva preeencher o "vácuo teórico e prático, captando as principais tendências presentes na opinião pública, entre as quais se destacam o controle dos gastos públicos e a demanda pela melhor qualidade dos serviços públicos".

Trata-se, portanto, de estabelecer uma nova organização do Estado e, sobretudo, sanar as debilidades da administração pública no que tange às dimensões institucional-administrativa e à participação do cidadão na administração pública.

Diante disso, mister se faz apresentar as principais manifestações da proposta gerencial no cenário administrativo, tanto no que diz respeito ao aspecto de estruturas, quanto de práticas de atuação nos respectivos setores da Administração Pública, empresarial e não empresarial, ressaltando, ainda, a necessidade de observância dos princípios constitucionais aplicáveis.

Além das exigências de ordem gerencial, a Reforma Administrativa também conferiu ênfase à densificação do princípio democrático, tornando necessário o desenvolvimento de mecanismos de participação do cidadão nos processos de tomada de decisões por parte da Administração Pública.

Portanto, o escopo deste artigo é verificar, no contexto da Administração Pública brasileira, os desafios e as implicações do modelo gerencial ante a perspectiva da democracia e seus princípios, regime de governo adotado pela República Federativa do Brasil.

Nessa contextualização indaga-se se quais os desafios que podem ser visualizados no âmbito da administração pública gerencial para que seja possível viabilizar a implementação do princípio democrático no âmbito da atuação da Administração Pública.

A metodologia utilizada para a realização desta pesquisa é de cunho bibliográfico, visto que se baseia em leitura e análise de publicações, tais como: livros, artigos, teses, dissertações, legislação, julgados. A abordagem da pesquisa é qualitativa, pois possui intuito de contribuir para ampliação do aporte teórico que versa sobre o assunto em análise.

A importância da presente pesquisa consiste em debater circunstâncias de um tema atual, porém com fronteiras antigas, bem como apresentar as inovações normativas e as práticas que se coadunam com os objetivos e princípios do Estado Democrático de Direito, por meio de uma Administração Pública que reclama a participação do cidadão.

\section{A REFORMA ADMINISTRATIVA GERENCIAL: SEUS PARADIGMAS E EXIGÊNCIAS}

A Reforma Gerencial do Estado ganhou projeção em todo o mundo, apresentando 
consequências e resultados diversificados, mesmo porque a adoção das medidas concernentes a este modelo ocorreu de modo mais ou menos intenso conforme cada Estado, não se olvidando que os fatores de cultura, história e lideranças políticas influenciaram diretamente na maneira e intensidade de concretização do projeto da Reforma.

Portanto, definir a Reforma Gerencial em um conceito padrão configura-se tarefa impossível, ou pelo menos pouco proveitosa, pois as perspectivas se apresentam as mais variadas, tanto no que diz respeito aos métodos de gerencialismo aplicados, quanto nas consequências de cada experiência.

Dessa forma, cumpre identificar a Reforma Gerencial a partir de características gerais e objetivos comuns que orientaram as experiências reformistas do final do século XX. A GrãBretanha desponta, na ótica de Bresser-Pereira (1998, p. 52), como um exemplo de mais bem sucedido e equilibrado caso de reforma gerencial no mundo.

Nos anos 1970, a Grã-Bretanha investe na mudança de administração pública com o escopo de alcançar o controle gerencial do serviço público, a partir da adoção de técnicas do mundo dos negócios e abordagem gerenciais nas estruturas administrativas que já existiam. No final dos anos 1970, com a eleição de Margareth Thatcher, a Grã-Bretanha experimenta um novo impulso em busca da eficiência a partir de uma reorganização interna do serviço público, com destaque para os aspectos de custos e orçamentos (BRESSER- PEREIRA, 1998, p. 53).

A reforma na Grã-Bretanha pautou-se na delegação de autoridade e nos contratos de gestão, e apresentou a adoção de um processo híbrido para escolha dos dirigentes das agências, esta última despontando como uma das principais mudanças. Assim, passou-se a ter um processo de seleção competitiva, com ampla abertura para concorrência aos cargos de dirigentes tanto para funcionários como para não funcionários, de modo a se obter um maior grau de responsabilidade e autonomia dentro das agências, na perspectiva de se alcançar maior eficiência no serviço público (BRESSER- PEREIRA, 1998, p. 54-55).

No Brasil a experiência da Reforma Administrativa da década de 1990 trouxe uma nova perspectiva quanto ao papel do Estado. De vilão responsável por todos os males que assolam a Administração Pública, passa a constituir-se em potencial protagonista na consolidação dos Direitos Fundamentais soerguidos pela Constituição Federal de 1988, sobretudo quanto a prover uma boa Administração Pública pautada na Eficiência e na Democratização.

O processo constituinte que resultou na Constituição Federal de 1988 consubstanciou-se em um embate que envolveu vários grupos, com o escopo precípuo de determinar os limites do arranjo social, econômico e político a ser estabelecido. Um cenário em que, de um lado, tinham- 
se as forças políticas do ancién regime, que lutavam para assegurar seu espaço neste novo cenário, e do outro, atuavam os representantes de forças da esquerda que, embora minoritários, adquiriram importante papel no processo constituinte (KINZO, 2001).

Na visão de Kinzo (2001), por ocasião do contexto social e político em que se deu a reconstitucionalização do país, era inevitável que o novo se entrelaçasse com o velho. Tal percepção destaca-se, sobretudo, pela reafirmação do legado da Era Vargas, com uma patente inclinação nacionalista e estatista de algumas de suas cláusulas econômicas e na preservação de muitos dos traços característicos da estrutura corporativa de representação de interesses.

Portanto, a ideia de uma Reforma Administrativa do Estado se mostrou necessária e urgente, ante o contexto do processo de democratização pelo qual o País passava, a crise política e econômica do governo Collor/ Itamar, e o governo de Fernando Henrique Cardoso, no qual se implementou o Plano Real com vistas à estabilização econômica para conter a inflação, e as sucessivas crises econômicas desencadeadas pelo México (1995); pela Ásia (1997) e pela Rússia (1998).

Com as medidas de ajuste fiscal, liberação comercial e de preços ainda em 1980, a primeira fase das mudanças na administração do Estado se mostrou irrealista do ponto de vista econômico ${ }^{1}$ e político ${ }^{2}$, o que ensejou o ingresso de uma nova fase já na década de 1990, onde implementou-se a reforma da Administração Pública com o objetivo precípuo de reconstruir o Estado (BRESSER-PEREIRA, 1998, p. 31).

A Reforma do Estado englobou vários aspectos da administração, que foram desde o plano fiscal; a reconstituição da poupança pública e a reforma da previdência social, com a configuração de reformas políticas que ensejavam uma ampliação da melhoria no aspecto da governabilidade, acrescida da reforma administrativa propriamente dita (BRESSER-PEREIRA, 1998, p. 32).

Contudo, a reforma gerencial na Administração Pública Brasileira na década de 1990 possuía alguns entraves a transpor para além daqueles próprios de uma transição de modelo organizacional. A transmutação da estrutura político-administrativa era o principal desafio a se vencer, visto que ainda apresentava ranços da burocracia patrimonialista que, envolta numa formalidade burocrática racional-legal se constituía na combinação perfeita para o entrave da democratização da Administração Pública.

Foi a partir dos objetivos políticos da sociedade contemporânea que a Reforma Gerencial da Administração Pública ensejou trazer uma definição do papel do Estado, com vistas a se buscar uma definição ampla, não apenas no que tange à perspectiva institucional-administrativa, 
como ocorreu com a Reforma Burocrática (racional-legal) do modelo anterior, mas adentrar nas dimensões econômico-financeira, bem como na sociopolítica.

Com efeito, a Reforma Gerencial, assim como as demais, partiu do pressuposto de que o Estado em grande número de áreas, em destaque para a social e a científica, poderia apresentar mais eficiência com a utilização de organizações públicas não estatais para a consecução dos serviços por ele apoiados. Tal ideia afastaria o a concepção neoliberal de que o Estado é intrínseco e generalizadamente ineficiente (BRESSER-PEREIRA, 1998, p. 32).

Como consequências, devem ser mencionados os processos de privatização ocorridos no final da década de $90^{4}$; a ênfase à atividade de regulação estatal por meio das agências reguladoras $^{5}$ e, por fim, o fomento ao Terceiro Setor, notadamente quanto ao desempenho de serviços de saúde, educação, cultura, por meio de Organizações Sociais, Organizações da Sociedade Civil de Interesse Público, Organizações da Sociedade Civil.

Quanto a tal aspecto revela-se importante pontuar, contudo, a necessidade de observância dos princípios constitucionais da publicidade, moralidade, eficiência e impessoalidade na escolha da entidade para celebrar a parceria com o Poder Público, não existindo permissão à arbitrariedade, tal como entendeu o Supremo Tribunal Federal ao julgar a ADI $1923^{6}$, levando, por tais razões, a constar da Lei n. 13.019/2014, que institui o regime jurídico do Terceiro Setor, a necessidade de chamamento público ${ }^{7}$ para seleção da organização da sociedade civil a firmar a respectiva parceria.

A Reforma Gerencial, nessa perspectiva teve, numa visão geral, o objetivo precípuo de aumentar a eficiência e efetividade dos órgãos do Estado a partir de um programa de descentralização, com abertura no processo decisório e assim obter um processo de "socialização do Estado", com mais participação a nível subnacional (NOGUEIRA, 2004, p. 54).

\footnotetext{
${ }^{4}$ Cabe mencionar, aqui, as Leis n. 8031, de 12 de abril de 1990 e 9.491, de 09 de setembro de 1997, que regulamentaram o Programa Nacional de Desetatização.

${ }^{5}$ No Brasil as agências reguladoras assumiram a forma de autarquias de regime especial, revelado pela seu poder normativo atribuído a tais entidades; pelos mandatos fixos de seus dirigentes serem dotados de mandatos fixos, possuindo, assim, maior independência perante o Poder Executivo. As primeiras agências criadas foram a Agência Nacional de Energia Elétrica-ANEEL, pela Lei no 9.427/96; a Agência Nacional do Petróleo-ANP, pela Lei no 9.478/97 a Agência Nacional de Telecomunicações-ANATEL, pela Lei no 9.472/97.

${ }^{6}$ Versou tal ação sobre a constitucionalidade da Lei no 9.637/98, que dispôs sobre as Organizações Sociais. Entendeu o STF, naquela ocasião, pela desnecessidade de realização de licitação para a celebração do contrato de gestão, quer pelo fato de não se estar a tratar da outorga, a tais entidades, de serviços de titularidade exclusiva do Estado, como saúde (CF, 196), educação (CF, art.206), cultura (CF, art.215) restando preservado, assim, o art.175 da CF; quer pelo fato de o contrato de gestão assumir mais a feição de um convênio do que de um contrato.

7 De acordo com o art.2으, XII da Lei no 13.019/2014 consiste o chamamento público no "procedimento destinado a selecionar organização da sociedade civil para firmar parceria por meio de termo de colaboração ou de fomento, no qual se garanta a observância dos princípios da isonomia, da legalidade, da impessoalidade, da moralidade, da igualdade, da publicidade, da probidade administrativa, da vinculação ao instrumento convocatório, do julgamento objetivo e dos que lhes são correlatos."
} 
Destaca-se assim que, em termos gerais, o modelo gerencial apresenta um caráter estratégico ou orientado por resultado do processo decisório; descentralização; flexibilidade; desempenho crescente; competitividade interna e externa, e, sobretudo, transparência e cobrança de resultados (accountability) (MARTINS, 1997, p. 65), uma das vertentes da governança corporativa, concepção gestada nos Estados Unidos como forma de proteção de acionistas minoritários, consoante esclarece Nohara (2018), dizendo esse último aspecto respeito ao setor empresarial.

Ainda segundo Nohara (2018) a governança corporativa, de acordo com o Código Brasileiro de Melhores Práticas, implica a adoção das seguintes medidas: a) a accountability (prestação de contas), e que se traduz, quanto à função administrativa, numa responsabilidade democrática, conduzindo, na explicação de Correia (2012, p.300), à adoção de uma dupla postura por parte da Administração Pública, a saber, a "sujeição, através da transparência ao escrutínio dos cidadãos e colaboração ativa com tal escrutínio, fazendo o razoavelmente exigível para do seu lado o possibilitar"; b) a transparência ou disclosure, levando em consideração, agora, os stakeholders, para que possam mensurar adequadamente os riscos dos investimentos e, por fim, a compliance, representada pela edição de códigos de ética ou códigos de integridade corporativa. ${ }^{8}$

O acesso a informações governamentais, indispensável à accountability, com a edição da Lei n. 12.527, de 18 de novembro de 2011, regulamentadora do art. $5^{\circ}$, XXXIII da CF (direito à informação), ganhou novas potencialidades, reveladas, por exemplo, pela necessidade de divulgação, pelos órgãos e entidades públicas, inclusive no âmbito da rede mundial de computadores (art. $8^{\circ}, \S 2^{\circ}$ ), de informações de "interesse coletivo ou geral por elas custodiadas", tais como repasses a eles, de quaisquer recurso ou transferência financeira (art.8, II), despesas realizadas (art. 8, III); procedimentos licitatórios (art.8, IV), dados sobre programas, obras, serviços a cargo deles ( art. 8, V). No âmbito federal, o Portal da Transparência cumpre tal função. ${ }^{9}$

Tal aspecto restou igualmente contemplado pela Lei n. 13.303, de 30 de junho de 2016, que, regulamentando o $\S 1^{\circ}$ do art.173 da $\mathrm{CF}$, instituindo o novo regime jurídico das empresas estatais, constando, de seu art. $8^{\circ}$, os requisitos mínimos de transparência ${ }^{10}$; de seu art. $12^{\circ}$ a

\footnotetext{
${ }^{8}$ A expressão compliance, fortemente ligada à matéria anticorrupção, significa, segundo Leal e Ritt (2018, p. 97), a "adesão da companhia a normas ou procedimentos de determinado setor", tendo surgido, no mundo empresarial, como instituição de controles internos, de modo a combater fraudes, corrupções, lavagem de dinheiro. E, segundo os autores, com a edição da Lei Anticorrupção (Lei 12.846/2013), o Brasil alinhou-se a importantes documentos internacionais sobre o tema.

${ }^{9}$ http://www.portaltransparencia.gov.br.

10 Dentre eles cabe citar a elaboração de carta anual com os "compromissos e as políticas públicas da entidade, os quais devem ser compatíveis com o interesse coletivo ou imperativo de segurança nacional que tenha justificado sua 
obrigatoriedade de divulgação de "toda e qualquer forma de remuneração de seus administradores"; ainda em tema de transparência, o art.85, $\S 1^{\circ}$ prevê o "acesso irrestrito dos órgãos de controle aos documentos e informações necessários à realização dos trabalhos, inclusive aqueles classificados como sigilosos" e o art. 86 determina a disponibilização de informações relativas a licitações e contratos e, "bancos de dados eletrônicos atualizados e com acesso em tempo real aos órgãos de controle", bem como das "informações contábeis auditadas das empresas públicas e sociedades de economia mista.” $\left(\S 1^{\circ}\right)$.

A legislação em comento traz a previsão de diversas medidas relacionadas à governança corporativa, de modo a possibilitar a "prática de gestão de risco, bem como o controle interno", nos termos de seu art. $9^{11}$.

Com intuito principal aprimorar os serviços, reduzir despesas e adequar a realidade administrativa aos objetivos democráticos, sobretudo no aspecto participativo, foi que se introduziram mecanismos utilizados pelo o modelo gerencial, que possui como fundamento as abordagens originalmente empresariais tais como a reengenharia ${ }^{8}$ e a gestão de qualidade total ${ }^{7}$, direcionando-as para organizações públicas.

A adoção desses métodos de empreendedorismo na administração pública, segundo Martins (1997, p. 63), consubstanciou-se em instrumentos com potencial racionalizador. Contudo, não se deve permitir o afastamento da matriz principiológica da Constituição, consoante visto acima, a qual não se resume à eficiência.

Também devem ser diferenciados os desafios próprios dos setores empresarial e não empresarial da Administração Pública, não sendo devida a mera transposição de pautas gerenciais, próprias do setor privado, para a realidade administrativa como um todo, tendo em vista a diversidade dos interesses a serem atingidos, em um e outro âmbito, não cabendo, dada a profundidade do tema, sua análise na presente pesquisa.

A adequação, por sua vez, entre os preceitos gerenciais, o texto constitucional e a legislação vigente foi necessária, sobretudo quanto à perspectiva da perfectibilização do princípio democrático na seara da Administração Pública, o que foi concretizado a partir da Emenda Constitucional n. 19/98, que será abordado a seguir.

criação, "com a definição clara dos recursos a serem empregados"; a adequação do seus estatuto social `autorização de sua criação; a divulgação das demonstrações financeiras e, bem como dos dados operacionais, bem como da política de transações; a carte de governança corporativa, bem como o relatório anual de sustentabilidade ( art. $8^{\circ}$, I s IX). 


\section{3- A MANIFESTAÇÃO DO PRINCÍPIO DEMOCRÁTICO NA NOVA PERSPECTIVA DA ADMINISTRAÇÃO PÚBLICA}

A reforma administrativa levada a efeito pela Emenda Constitucional n. 19, além de trazer, para o plano da Administração Pública, paradigmas relacionados a práticas gerenciais, que privilegiam o princípio da eficiência, com todos os seus consectários, também expressou a necessidade de participação do cidadão na tomada de decisões por parte do Poder Público, tal como ensejam as prerrogativas previstas no $\S 3^{\circ}$ do art. 37 da CF relativas à formulação de reclamações sobre a prestação dos serviços públicos em geral, o acesso a informações sobre atos de governo e a representação contra exercício abusivo da função pública.

Trata-se do inevitável aprofundamento do princípio democrático, de "democratização da democracia", nas palavras de Otero (2016, p. 326), a qual reclama a ouvida e a manifestação da sociedade e de seus membros em diversos outros momentos e assuntos que não apenas os pleitos eleitorais, encontrando-se previsões semelhantes à constante no texto constitucional brasileiro nas Constituições portuguesa e espanhola. ${ }^{12}$

Com efeito, a Administração Pública de um Estado Democrático de Direito, fundado na dignidade da pessoa humana $\left(\mathrm{CF}\right.$, art. $\left.1^{\circ}, \mathrm{III}\right)$, da qual decorrem os direitos fundamentais, não se compatibiliza com atuações administrativas de caráter exclusivamente unilateral, tanto no que diz respeito à forma de consulta e consideração dos direitos e interesses envolvidos em dada situação, quanto no tocante aos instrumentos utilizados para seu equacionamento e adoção de soluções.

Por sua vez, a atualizada concepção de interesse público, cuja identificação, nas situações concretas, depende de inevitáveis procedimentos de ponderação, pelo administrador, de bens e valores à luz da Constituição, segundo Binebojm (2006, p. 105) e Sarmento (2006, p. 271), não mais podendo ser compreendido a partir de perspectiva apriorística, o que também é resultante do declínio de uma legalidade própria do Estado Liberal, bem como da incorporação de outras pautas de vinculação normativa da Administração Pública, como os princípios com seus mandatos de otimização e a pluralidade de formas de conduta admissíveis a partir deles.

Assim, avaliações unilaterais fundadas em informações que desconsideram não apenas o caráter plural da sociedade, como, também, a diversidade das fontes a serem consultadas, não

\footnotetext{
12 A Constituição portuguesa prevê em seu art. 267, inciso I, alínea "b", o incentivo à desburocratização, à aproximação dos serviços da população. Já a Constituição espanhola, em seu art. o art. 105, alíneas "a" e "c" cuida da participação do cidadão na esfera administrativa por meio de um direito de audiência, diretamente ou por meio de organizações e associações e o seu art. 129 atribui ao legislador a tarefa de estabelecer formas de participação dos cidadãos nas atividades dos organismos públicos.
} 
dão conta de oferecer respostas atuais e adequadas, de modo que a participação cidadã pode desempenhar relevante função na definição daquele.

Por outro lado, as pretensões decorrentes dos direitos fundamentais, vão para além de ensejar o dever de proteção deles por parte do Poder Público, o direito as prestações, segundo a vertente desenvolvida por Häberle, descrita por Sarlet (praticamente um apud, melhor substituir) (2003, p.164) do status ativus processualis, a tomarem parte nas instâncias de procedimento e organização, o que conflui para a elaboração da noção de cidadania administrativa, da qual decorreria, na percepção de Otero, a democracia administrativa (2016, p. 326).

Otero parte de uma "concepção personalista" (2016, p. 319) da Administração Pública, certamente em nada identificada com a Administração patrimonialista, decorrente na realidade, da dignidade da pessoa humana, como fim e fundamento da atuação administrativa e da vinculação daquela aos direitos fundamentais.

Da mesma forma, na Espanha, Muñoz (2011, p. 77) reporta-se à centralidade da posição do cidadão nas construções modernas de Administração Pública e de Direito Administrativo, o qual já não seria apenas um sujeito inerte perante aquela, destinatário de suas atuações, passando a ter um protagonismo na definição e avaliação de políticas públicas. Semelhante perspectiva, no seu entender, seria essencial na compreensão do direito fundamental à boa administração pública, trazido pela Carta de Direitos Fundamentais da União Europeia, em seu art. $41 .^{13}$

Coetânea a tal forma de compreensão do cidadão perante a Administração Pública se encontra a ideia de cidadania administrativa tratada por Otero (2016, p. 326), a qual considera as posições jurídicas ativas dos particulares perante da Administração Pública, e não apenas destinatários da sua atuação, tornando, no seu entender, obsoletas referências àqueles como "súdito, administrado, consumidor, cliente ou utente" (2016, p. 323), ou seja, numa permanente relação geral de sujeição perante o Poder Público.

O exercício da cidadania administrativa, ainda de acordo com Otero (2016, p. 326), possui como manifestações, além dos clássicos direito de petição, queixa, ação popular, a manifestação pela preferência a formas consensuais de atuação, mediante procedimentos negociais e concertados; reforça o direito de participação de todos os interessados, inclusive mediante procedimentos informais; reclama transparência no agir e direito

\footnotetext{
${ }^{13}$ De acordo com o citado artigo da referida carta, compreende a boa administração o seguinte: direito pelos cidadãos da União Europeia, de ter seus assuntos tratados de forma imparcial e equitativa, dentro de um tempo razoável; o direito de ser ouvido antes da adoção de medidas que lhes sejam desfavoráveis; o direito ao acesso a expedientes que digam respeito a seus interesses, dentro de confidencialidade e segredo profissional; o direito à motivação das decisões; o direito à indenização por danos causados por instituições da Comunidade Europeia.
} 
à informação.

Considerando, ainda, a nova dimensão da atuação administrativa, marcada pela busca da consensualidade, a qual requer a adoção de postura dialogal da Administração Pública, necessário ao particular que com ela interage a efetiva possibilidade de contribuir para a formação de suas decisões, o que demanda procedimentos e organizações funcionais devidamente estruturados para tanto, além de instrumentos concretizadores do resultado dos diálogos.

E, a propósito da "atuação soberana consensual", na expressão de Estorninho (1999, p. 44), nela há, de fato, a substituição de tradicionais atos unilaterais de autoridade por medidas e decisões negociadas nas quais o administrado (ou numa expressão mais atualizada e carregada de simbolismo, o cidadão) deixa de ser mero destinatário daqueles. E mesmo em se tratando de atos unilaterais a sua edição é perfeitamente compatível com "mecanismos institucionalizados de audição e participação dos interessados” (BATISTA JÚNIOR, 2012, p. 247).

Na realidade, a adoção da consensualização administrativa, ou da soft administration não implica, e nem poderia implicar, na eliminação das prerrogativas públicas, como a imperatividade e o poder extroverso, reclamando, na realidade, a compatibilização delas "com a lógica do consenso", consoante destaca Faleiros (2017, p.71).

Se a procedimentalização da atividade administrativa já representava exigência para sua legitimação, controlando a forma de exercício do poder, a busca pela consensualidade e concertação vai além da formal previsão de manifestação dos cidadãos antes da aplicação de medidas que lhes afetem de forma desfavorável, visando, de fato, à formulação de decisões que revelem o consenso possível, em dado momento.

A reforma da Administração Pública desenhada pela Emenda Constitucional n. 19 não pode, portanto, ser compreendida unicamente pelas exigências gerenciais que ela veicula, com vistas a superar o modelo burocrático de atuação, sendo necessário intensificar e desenvolver as formas de democracia administrativa, a qual se conecta inelutavelmente com o cidadão.

Resta analisar em que medida tal participação pode ser dar resguardando, sempre, os objetivos maiores a serem realizados pela Administração Pública, bem como os valores que ela representa.

\section{4- MEIOS DE EFETIVAÇÃO DA DEMOCRACIA ADMINISTRATIVA}

A abertura da Administração Pública à participação cidadã e a preferência por formas adequadas de atuação devem se dar dentro das hipóteses e instrumentos viabilizados pela ordem 
jurídica, sendo importante atentar, inicialmente, para as disposições do art. $37, \S 3^{\circ}$, da CF e que se refere, consoante mencionado acima, à edição de lei que preveja formas de participação do "usuário" no serviço público, quer mediante reclamações, quer mediante representação contra formas abusivas de exercício do poder, além de acesso a informações e atos de governo.

A participação do cidadão na Administração Pública, para além da formulação de reclamações e representações perante os seus órgãos de controle interno (corregedorias, controladorias, ouvidorias) deve se dar fundamentalmente na formação das decisões administrativas, as quais devem refletir a pluralidade de pontos de vista como forma de obtenção de consensos.

Como representações dessa nova forma de atuação administrativa tem-se a previsão, já na Lei n. 9.784/99, que regulou o processo administrativo no âmbito da Administração Pública Federal, de realização de consultas e audiências públicas antes da tomada de decisões de interesse geral por parte da Administração Pública, ultrapassando os interesses meramente individuais, ainda que haja discricionariedade a propósito de sua deflagração. ${ }^{14}$

Da mesma forma, a Lei da Responsabilidade Fiscal (Lei Complementar n. 101/2000), bem como o Estatuto da Cidade (Lei n. 10.257/2001) contemplam a realização de audiências públicas para a elaboração de Lei de Diretrizes Orçamentárias, Lei Orçamentária Anual e dos Planos Diretores.

Por sua vez, a Lei n. 12.401/2011 estabelece a obrigatoriedade das consultas públicas em sede de procedimento para incorporação de novas tecnologias ao Sistema Único de Saúde, as quais devem ser feitas após a elaboração do relatório conclusivo pela CONITEC- Comissão Nacional de Incorporação de Tecnologias, órgão de composição plural, integrante do Ministério da Saúde, nos termos do art.19 -R§ 1, III do referido diploma normativo. Já a realização de audiência pública sobre o tema fica submetida à relevância da material (art. 19-R, IV da Lei 12.401/2011, a critério do Secretário de Ciência, Tecnologia e Insumos Estratégicos do Ministério da Saúde, de acordo com o art. 21 do Decreto n. 7646/2011.

Um panorama do elenco de audiências e consultas públicas no âmbito da Administração Pública Federal consta do site "www.brasil.gov.br/consultas-públicas", onde se encontram discriminadas por área, entidade e ano aquelas já realizadas e as que se encontram em andamento.

\footnotetext{
${ }^{14}$ Nos termos do art. 31 da Lei 9.784/99, in verbis: "Quando a matéria do processo envolver assunto de interesse geral, o órgão competente poderá, mediante despacho motivado, abrir período de consulta pública para manifestação de terceiros, antes da decisão do pedido, se não houver prejuízo para a parte interessada." Já o art. 32 possui a seguinte redação: "Antes da tomada de decisão, a juízo da autoridade, diante da relevância da questão, poderá ser realizada audiência pública para debates sobre a matéria do processo" (BRASIL, 1999).
} 
Se, em muitos casos, a natureza eminentemente técnica da matéria pode afastar a participação do cidadão que não possua com ela maior envolvimento, em se tratando de tema que reflita sobre questão sensível para a maioria da sociedade, acabam sendo apresentadas contribuições que versam sobre aspectos práticos de dada medida.

Exemplo recente da adoção de consulta pública em matéria de significativo relevo deu-se a propósito da realização do Exame Nacional de Ensino Médio-ENEM, no ano de 2017, ocasião em que o Instituto Nacional de Estudos e Pesquisas Educacionais Anísio Teixeira- INEP, antes de divulgar o Edital que trouxe as novas regras para o certame, colheu opiniões da sociedade, tendo sido apresentadas, antes da prorrogação da consulta, 414 (quatrocentos e quatorze) mil sugestões. ${ }^{15}$ Tal providência, reveladora da busca de consensos, teve também a finalidade de prevenir ou ao menos reduzir judicialização sobre pontos supostamente mais polêmicos.

A experiência acima revela o papel da cidadania administrativa no aperfeiçoamento de importante política pública que concretiza o direito fundamental à educação, no sentido de adaptar, na medida do possível, a realização de exame de grande magnitude e complexidade às demandas e dificuldades de seus participantes.

Resultados positivos podem ser também apontados em outras áreas, como é o caso do direito à saúde, âmbito em que os Conselhos e as Conferências de Saúde, criados pela Lei Federal n. 8.142/90, são instâncias tanto de participação nas políticas públicas em tal área como também de seu controle social, ainda que sejam apontadas insuficiências na intervenção da sociedade civil, bem como a necessidade de aprimorá-la, por meio várias medidas como melhor capacitação de conselheiros e a preservação dos espaços de representação, próprios dos usuários (GUIZARDI, 2012, p. 592).

Quanto à construção de decisões concertadas, merece referência a possibilidade de celebração de Termos de Ajustamento de Conduta entre a Administração e particulares, ou mesmo entre entidades administrativas com vistas a regular formas, condições, prazos de cumprimento de dada determinação normativa, de acordo com a Lei n. 7.347/85, em seu art. $5^{\circ}$, $\S$ $6^{\text {o16 }}$ e, agora, recentemente, reiterado pela Lei n.13.140/2016 ${ }^{17}$ (Lei da Mediação).

\footnotetext{
15 Informações sobre a consulta pública podem ser obtidas no site portal.inep.gov.br. Dentre as mudanças realizadas no ENEM de 2017, destacaram-se a data de realização da prova de redação (no primeiro domingo e com duração de 5:30h) e a perda do caráter de certificação do ENEM.

${ }^{16}$ [...] $\S 6^{\circ}$ "Os órgãos públicos legitimados poderão tomar dos interessados compromisso de ajustamento de sua conduta às exigências legais, mediante cominações, que terá eficácia de título executivo extrajudicial” (BRASIL, 1985).

17 Art. 32. [...]

III - promover, quando couber, a celebração de termo de ajustamento de conduta.
} $[\ldots]$ 
Ou seja, em vez de a Administração impor, de maneira unilateral, o cumprimento de determinada obrigação aos cidadãos, incentiva-os a aderir àquela, mediante a possibilidade de estabelecimento de prazos e condições que, geralmente lhes sejam favoráveis, embora não se possa deixar de lado, em tais negociações, o princípio da legalidade.

Quer se compreenda os termos de ajustamento como contratos administrativos de transação strictu sensu, tal como trata, Batista Júnior (2007, p. 450), ou como contrato administrativo alternativo, importante é que a celebração deles seja de fato resultado de construção dialogal, e não um simulacro de acordo, ao qual simplesmente adere o particular.

Outra perspectiva que também revela uma abertura dialogal da Administração Pública em relação à sociedade diz respeito à possibilidade de resolução de conflitos entre ela e os cidadãos por meio de composição no âmbito das câmaras de mediação e conciliação, vinculadas aos órgãos da Advocacia Pública, nos termos da Lei n 13.140/2016 (Lei da Mediação) inclusive com previsão de utilização de procedimento de mediação coletiva para resolver conflitos relacionados à prestação de serviços públicos, de acordo com seus art.32, inciso III e 33, parágrafo único ${ }^{18}$ da referida lei.

A composição administrativa de conflitos pode contribuir, sensivelmente, para a redução da litigiosidade para com o Poder Público, concretizando, assim, o princípio da eficiência, na medida em que eliminaria os custos da judicialização, além de proporcionar interação direta entre aquele e o cidadão, sem intermediação do Poder Judiciário, levando à procura de satisfação de interesses mediante consensos, com redução também de tempo, dentro, certamente, da ordem jurídica ${ }^{19}$ e do princípio da legalidade.

A partir, portanto, da previsão do $\S 3^{\circ}$ do art. 37 da $\mathrm{CF} / 88$ podem ser desenvolvidas diversas formas de densificação do princípio democrático, cabendo ressaltar, por fim, a recente edição da Lei n. 13.460, de 26/06/2017, e que a título de regulamentar o $\S 3^{\circ}$ do art. 37 da CF, “estabelece normas básicas para proteção e defesa dos direitos dos usuários dos serviços públicos, disciplinado, dentre outras questões, os direitos básicos e deveres dos usuários (art. $5^{\circ}$ ); as manifestações dos usuários do serviço público (art. 9º)" (BRASIL, 1988).

Referida lei compila, atualiza e desenvolve previsões já constantes da Lei 8.987/90 sobre

$\S 3^{\circ}$ Se houver consenso entre as partes, o acordo será reduzido a termo e constituirá título executivo extrajudicial (BRASIL, 2016).

${ }^{18}$ Art. 32. A União, os Estados, o Distrito Federal e os Municípios poderão criar câmaras de prevenção e resolução administrativa de conflitos, no âmbito dos respectivos órgãos da Advocacia Pública, onde houver, com competência para:

$[\ldots]$

II-avaliar a admissibilidade dos pedidos de resolução de conflitos, por meio da composição, no caso de controvérsia entre particular e pessoa jurídica de direito publico (BRASIL, 1988). 
a noção de serviço adequado (art. $6^{\circ}$ ); bem como aquelas constantes da Lei Geral de Processo Administrativo (Lei n. 9.784/99) sobre os princípios que lhes são aplicáveis, os critérios a serem adotados em tal âmbito pela Administração Pública (art. $2^{\circ}$ ) e sobre os direitos e deveres dos administrados (arts. $3^{\circ}$ e $4^{\circ}$ ), acrescentando temas como a definição das competências das ouvidorias (arts. 13, 14 e 15); a previsão de criação dos conselhos de usuários (art. 18) e a avaliação contínua dos serviços (art. 23).

Merece registro o fato de a legislação brasileira continuar a utilizar-se das expressões "administrado" e "usuário", insuficientes para expressar a ideia de "cidadania administrativa", embora não comprometa os importantes objetivos de fortalecimento das situações das pessoas físicas e jurídicas perante a Administração Pública.

Verifica-se assim que apesar do leque de opções passíveis de viabilizar a efetiva implementação de uma democracia administrativa que passe, por conseguinte a executar no plano fático os princípios constitucionais estabelecidos à Administração Pública, alguns óbices ainda precisam restar por solucionados, de modo que se deva buscar afastar as limitações impostas à democracia administrativa.

\section{DESAFIOS E LIMITES À DEMOCRACIA ADMINISTRATIVA}

A verticalização e ampliação dos meios de exercício da democracia no âmbito da Administração Pública têm como desafios tanto incluir a sociedade civil nos debates acerca das decisões administrativas e consecução das políticas públicas, como, também, preservar o campo de responsabilidade próprio daquela.

No que diz respeito ao primeiro aspecto não se pode deixar de considerar que, por exemplo, o caráter altamente técnico de determinadas questões não venha a, tendencialmente, afastar ou desestimular a manifestação e o comparecimento dos cidadãos nos foros de debate, ocorrendo exatamente o inverso no tocante àqueles temas que não demandem conhecimento especializado, como foi o caso da Consulta Pública a propósito do ENEM-2017.

Ainda que não se possa desprezar tal realidade constitui, assim, um dos desafios na intensificação da participação da sociedade, a disponibilização, pela Administração Pública, da forma mais acessível quanto possível, dos dados técnicos acerca de determinada questão, bem como sobre as consequências e implicações que as escolhas acarretarão, fazendo-se com que a argumentação especializada, científica, não seja um fator de distanciamento e desinteresse por parte dos cidadãos.

Perante os conselhos de saúde, por exemplo, Guizardi (2012, p. 587) chama a atenção para o fato de que a argumentação técnico-científica é utilizada para desautorizar o 
posicionamento dos representantes da comunidade e desprezar suas experiências, o que findaria por transformar os conselhos em instâncias meramente burocráticas.

Necessário, portanto, buscar a tomada de decisões que, ao mesmo tempo não se afastem do conhecimento científico, de dados e elementos de natureza técnica, o que de certo não seria razoável, colocando-os, todavia, na medida possível, acessíveis à sociedade civil, de forma que o caráter técnico, especializado de dado tema não venha a ser um empecilho a uma participação efetiva.

Apesar de a participação dos cidadãos na Administração Pública se constituir em uma exigência da democracia, não se pode deixar de atentar para alguns perigos que ela pode trazer, até para que possam ser, na medida do possível, equacionados. E, um dos riscos, diz respeito exatamente à igualdade e à impessoalidade, em virtude das diferenças existentes entre os particulares, já que alguns são, de fato, detentores de maiores meios econômicos, de informações, ou mesmo de uma maior proximidade para com os centros de poder (NETTO, 2009, p. 130-131).

Semelhante circunstância pode transformar "a atuação administrativa, essencialmente pública, voltada para o bem comum, numa atividade privatizada, voltada para a busca de interesses privados, de indivíduos ou grupos de particulares" (NETTO, 2009, p.131).

Há outros riscos decorrentes da participação da sociedade civil na Administração Pública sem os devidos contrapontos, como a diluição da responsabilidade dessa última, aspecto referido na doutrina portuguesa, ainda segundo Netto (2009, p. 120).

No que diz respeito à preservação dos espaços de competência da Administração Pública, Ruiz (2011, p. 58) chama a atenção para o risco de "diluição do princípio básico de responsabilidade no processo de direção e implementação política". Assim, a repartição de processos decisórios com a sociedade civil pode levar à transferência, a ela, da responsabilidade por eventuais insucessos das políticas públicas e decisões administrativas, o que viola também as atribuições de competências previstas na Constituição, as quais são indisponíveis (RUIZ, 2011, p. 58).

Uma coisa seria a existência de "circuitos institucionais de fórmulas de democracia participativa”, nas palavras de Ruiz (2011, p. 58), como consultas populares, tele-democracia e outras, diversa, é a indevida subtração da responsabilidade administrativa pública. Para o autor, a participação popular não pode se dar no plano da titularidade da competência funcional, quedando adequada na dimensão executiva.

Certamente sem perder a perspectiva de que o acesso à informação revela-se 
indispensável para a participação dos cidadãos na Administração Pública, não se pode deixar de atentar para a existência de questões que necessitam ficar resguardadas pelo sigilo, e cujas hipóteses estão descritas no art. 23 da Lei n 12.537/2011, consoante acima referido, existindo, também, na Lei n. 13.303/2016 a ressalva, quanto à divulgação de informações resguardadas por sigilo bancário, estratégico, comercial ou industrial, com a responsabilização do agente público responsável por sua indevida divulgação (art. 86, § $\left.4^{\circ}\right)$.

Assim, as formas de participação do cidadão na Administração Pública necessitam restar comprometidas com a realização das finalidades precípuas e específicas da sua atuação, não podendo se transformar em meros formalismos e muito menos, em pretextos para a "colonização" de decisões administrativas por grupos mais poderosos e organizados, preocupação de resto já colocada quanto à atividade de regulação do Estado, tal como destacam Moreira (1997, p.49) e Justen Filho (2002, p. 360-369).

Por sua vez, no que diz respeito à mencionada composição de conflitos entre a Administração Pública e os particulares no âmbito administrativo, não se pode perder de vista a vinculação de tal atuação à legalidade e aos princípios constitucionais da Administração Pública, cabendo sempre ao ente público indicar, em regulamento, os assuntos a serem levados às câmaras, ${ }^{20}$ bem como os critérios mínimos e pautas de negociação.

\section{CONCLUSÃO}

A reforma administrativa produzida pela Emenda Constitucional n. 19/98 reformulou o papel do setor público brasileiro com base em experiências de outros países mediante o redimensionamento da máquina estatal, mudança de enfoque em suas atribuições e da forma de desempenhá-las, primando pela realização das exigências do princípio da eficiência. Tal deve ser feito, todavia, com as devidas matizações, a depender de se estar diante do setor público empresarial ou não empresarial.

Entra em cena, assim, a adoção de práticas relativas à governança corporativa, como a accountability, a transparência e a compliance, presentes na lei que instituiu o novo regime jurídico das empresas estatais (Lei n. 13.303/2016), estando alguns aspectos também já presentes na Lei de Acesso à Informação (Lei n. 12.527/2011), aplicável a todo o setor público.

Todavia, a Administração gerencial, a título de concretizar o princípio da eficiência, não pode desprender-se dos demais princípios constitucionais do art.37, caput, da $\mathrm{CF} / 88$, realidade

\footnotetext{
${ }^{20}$ De acordo com o art. 32, §2ㅇ da Lei 13.140/2016: Parágrafo único. A Advocacia Pública da União, dos Estados, do Distrito Federal e dos Municípios, onde houver, poderá instaurar, de ofício ou mediante provocação, procedimento de mediação coletiva de conflitos relacionados à prestação de serviços públicos (BRASIL, 2016).
} 
que restou evidente por ocasião do julgamento, pelo Supremo Tribunal Federal, da ADI 1923, a propósito das parcerias estabelecidas ente a Administração Pública e o Terceiro Setor, carecendo, ainda, levar em consideração seus específicos objetivos e finalidades, não cabendo a mera transposição de práticas do setor privado.

Em virtude, por sua vez, do princípio democrático, há a incorporação da participação do cidadão ao processo de tomada de decisões da Administração Pública, o que irá exigir a adoção de meios e instâncias adequados para ensejá-la, passando a ser insuficientes as tradicionais formas unilaterais de atuação administrativa.

Para refletir a pluralidade social e a busca de consensos desenvolveram-se assim instrumentos como as audiências e consultas públicas, os termos de ajustamento de conduta, os conselhos de participação do usuário na Administração Pública. E, embora a manifestação cidadã possa se fazer mais fácil em temas que não demandem conhecimentos de natureza técnica, tal circunstância não deve servir para inviabilizar ou desconsiderar a abertura da instância administrativa à sociedade.

O desafio da intensificação da participação popular na Administração Pública não pode, contudo, levar a distorções representadas, por exemplo, por sua captura por grupos de particulares mais influentes, quer pelo domínio de informações, quer pela proximidade com o poder, ou então pela diluição da responsabilidade do Estado na implementação de políticas públicas e na tomada de decisões de modo geral, não se podendo jamais perder de vista a realização das finalidades precípuas e específicas da atuação administrativa.

Por fim, a resolução de conflitos entre a Administração Pública e os cidadãos por meio de composição administrativa, não pode afastar-se da vinculação à legalidade e aos demais princípios constitucionais.

\section{REFERÊNCIAS}

ABRÚCIO, F. L. O impacto do modelo gerencial na administração pública: um breve estudo sobre a experiência internacional recente. Cadernos ENAP, Brasília, n. 10, 1997. Disponível em: https://goo.gl/Ce3jn3 . Acesso em: 02 jul. 2018.

BATISTA JR., Onofre Alves. Transações administrativas: um contributo ao estudo do contrato administrativo como mecanismo de prevenção e terminação de litígios e como alternativa à atuação administrativa autoritária, no contexto de uma Administração Pública mais democrática. São Paulo: Quartier Latin, 2007.

BINENBOJM, Gustavo. Uma Teoria do Direito Administrativo. Rio de Janeiro: Renovar, 2006. 
BRESSER-PEREIRA, Luiz Carlos. Reforma do Estado para cidadania - a reforma gerencial brasileira na perspectiva internacional. São Paulo: 34, 1998.

CORREIA, Sérvulo. Controlo judicial da Administração e responsabilidade democrática da Administração. Direito Administrativo e Direitos Fundamentais: diálogos necessários. Belo Horizonte: ed. Fórum, 2012, pgs. 299-311.

ESTORNINHO, Maria João. A fuga para o Direito Privado. Coimbra: Almedina, 1999.

FALEIROS JÚNIOR. A Administração Pública consensual: novo paradigma de participação dos cidadãos na formação das decisões estatais. Revista Digital de Direito Administrativo da Faculdade de Direito de Ribeirão Preto. São Paulo, v.4, n.2, 2017 disponível em: www.revistas.usp.br/rdda. Acesso em 09 nov 2018.

FAORO, Raymundo. Os donos do poder: formação do patronato político brasileira, $3^{\mathrm{a}}$ ed. São Paulo: Globo, 2001.

FREITAS, Juarez. Direito Fundamental à boa administração. 3. ed. São Paulo: Malheiros, 2007.

GUIZARDI, Francini Lube. Direito à Saúde e a Participação Política no SUS: cenários, dispositivos e obstáculos. In: ASENSI, Felipe Dutra

PINHEIRO, Roseni (Org.). Direito Sanitário. Rio de Janeiro: Campus Jurídico, 2012, p. 583596.

JUSTEN FILHO, Marçal. O Direito das Agências Reguladoras Independentes. São Paulo: Dialética, 2002.

KINZO, Maria D'alva Gil. A democratização brasileira: um balanço do processo político desde a transição. São Paulo Perspec. São Paulo, v. 15, n. 4, out./dez. 2001. Disponível em: https://goo.gl/JZ2KzF . Acesso em: 20 dez. 2018.

MARTINS, Humberto Falcão. Burocracia e a Revolução Gerencial- A persistência da dicotomia entre política e administração. Revista do Serviço Público - RSP, Brasília, ano 48, n. 1, p. 4276, jan./abr. 1997.

MOREIRA, Vital. Auto-regulação Profissional e Administração Pública. Coimbra: Almedina, 1997.

MUÑOZ,JaimeRodriguezArana.El derecho fundamentala la buena administracion de institucione s publicas y el derecho administrativo. In: RODRIGUEZ, Carmen Maria Avila; RODRIGUEZ, Francisco Gutierrez. (Org.). El derecho a una buena administracion y la ética publica. Valencia: Tirant lo blanch, 2011, p. 77-105.

NETTO, Luísa Cristina Pinto. Participação administrativa procedimental: natureza jurídica, garantias, riscos e disciplina adequada. Belo Horizonte: Fórum, 2012.

NOGUEIRA, Marco Aurélio. Um Estado para a sociedade civil - Temas éticos e políticos da gestão democrática. São Paulo: Cortez, 2004. 
NOHARA, Irene. Mudanças promovidas pela nova Lei das Estatais: pontos fortes e fracos. Disponível em: www.direitoadm.com.br Acesso em 09/09/2018.

OTERO, Paulo. Manual de Direito Administrativo. Coimbra: Almedina, 2016.

RITT, Caroline Fockint e LEAL, Rogério Gesta. A Necessidade de Adoção de Códigos de Integridade Corporativa-Compliance-pelas Entidades da Administração Pública Indireta de Direito Privado. Revista da AGU. Brasília, Ano 17, no 02, abril/jun 2018, pgs.87/107.

RUIZ, Gerardo Ruiz-Rico. El Derecho a una buena administracion. Dimensiones Constitucional y Estatutaria. In: RODRIGUEZ, Carmen Maria Avila; RODRIGUEZ, Francisco Gutierrez. (Org.). El derecho a una buena administracion y la ética publica. Valencia: Tirant lo blanch, 2011, p. 55-75.

SARLET. Ingo. A eficácia dos direitos fundamentais. Porto Alegre: Livraria do Advogado, 2003.

SARMENTO, Daniel. Colisões entre Direitos Fundamentais e Interesses Públicos. In: GALDINO, Flávio; SARMENTO, Daniel. (Org.). Direitos Fundamentais: estudos em homenagem ao professor Ricardo Lobo Torres. Rio de Janeiro: Renovar, 2006, p. 269-329. 